\title{
Neural progenitor cells attenuate inflammatory reactivity and neuronal loss in an animal model of inflamed AD brain Jae K Ryu ${ }^{\dagger 1}$, Taesup Cho ${ }^{\dagger 2}$, Yu Tian Wang² and James G McLarnon*1
}

Address: ${ }^{1}$ Department of Anesthesiology, Pharmacology and Therapeutics, University of British Columbia, Vancouver, British Columbia V6T 1Z3, Canada and ${ }^{2}$ Brain Research Centre, Vancouver Coastal Health Research Institute, University of British Columbia, Vancouver, British Columbia V6T 1Z3, Canada

Email: Jae K Ryu - JKRyu72@gmail.com; Taesup Cho - cts11@interchange.ubc.ca; Yu Tian Wang - ytwang@brain.ubc.ca; James G McLarnon* - mclarnon@interchange.ubc.ca

* Corresponding author †Equal contributors

Published: 23 December 2009

Journal of Neuroinflammation 2009, 6:39 doi:10.1 186/I742-2094-6-39
Received: 7 August 2009

Accepted: 23 December 2009

This article is available from: http://www.jneuroinflammation.com/content/6/1/39

(C) 2009 Ryu et al; licensee BioMed Central Ltd.

This is an Open Access article distributed under the terms of the Creative Commons Attribution License (http://creativecommons.org/licenses/by/2.0), which permits unrestricted use, distribution, and reproduction in any medium, provided the original work is properly cited.

\begin{abstract}
Background: Transplantation of neural progenitor cells (NPC) constitutes a putative therapeutic maneuver for use in treatment of neurodegenerative diseases. At present, effects of NPC transplantation in Alzheimer's disease (AD) brain are largely unknown and a primary objective of this work was to demonstrate possible efficacy of NPC administration in an animal model of AD. The benefits of transplantation could involve a spectrum of effects including replacement of endogenous neurons or by conferring neuroprotection with enhancement of neurotrophic factors or diminishing levels of neurotoxic agents. Since chronic inflammation is a characteristic property of AD brain, we considered that transplantation of NPC could have particular utility in inhibiting ongoing inflammatory reactivity. We have tested intrahippocampal transplantation of NPC for efficacy in attenuating inflammatory responses and for neuroprotection in beta-amyloid $\left(A \beta_{I-42}\right)$ peptide-injected rat hippocampus.
\end{abstract}

Methods: Spheres of neural progenitor cells were grown from dissociated telencephalon tissue of rat embryos. NPC were infected with lentiviral vector green fluorescent protein (GFP) with subsequent cell transplantation into rat hippocampus previously injected ( $3 \mathrm{~d}$ prior) with $A \beta_{\mathrm{I}-42}$ peptide or PBS control. Immunohistochemical analysis was carried out (7 d post-NPC transplantation, $10 \mathrm{~d}$ post-peptide/PBS injection) for GFP, microgliosis (Iba-I marker), astrogliosis (GFAP marker), neuron viability (MAP-2 marker) and levels of the proinflammatory cytokine, TNF- $\alpha$.

Results: Successful infection of cultured NPC with lentiviral vector green fluorescent protein (GFP) was demonstrated prior to cell transplantation into rat hippocampus. In vivo, immunohistochemical staining showed migration of GFPpositive cells, in a region of dentate gyrus between $A \beta_{\text {I-42 }} / \mathrm{PBS}$ injection site and NPC transplantation site, was increased $\times 2.8$-fold with $A \beta_{1-42}$ compared to PBS injection. Double immunostaining in peptide-injected brain indicated GFP association with nestin and GFAP, but not MAP-2. Cell-specific immunostaining showed marked increases in microgliosis

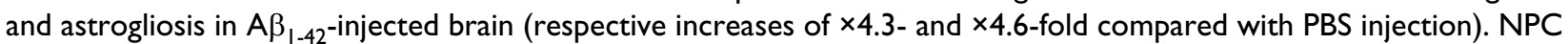
transplantation significantly reduced microgliosis (by $38 \%$ ) but not astrogliosis in peptide-injected hippocampus. The proinflammatory cytokine TNF- $\alpha$ was elevated by 6.7 -fold (peptide vs PBS injection) with NPC administration attenuating levels of TNF- $\alpha$ (by 40\%). Peptide-injected brain demonstrated neuronal loss (MAP-2 staining reduced by $45 \%$ vs PBS injection) with NPC transplantation effective in conferring neuroprotection (26\% recovery of neurons).

Conclusions: These findings indicate efficacy for NPC transplantation in an animal model of AD with effects consistent with cellular actions to attenuate inflammatory reactivity induced by intrahippocampal peptide injection. 


\section{Background}

Alzheimer's disease (AD) is a chronic neurodegenerative disorder that in advanced stages is characterized by increased levels of amyloid-beta (A $\beta$ ) peptide deposits, neurofibrillary tangles, abnormalities in neuronal and synaptic function and evidence for ongoing inflammatory reactivity $[1,2]$. The changes in underlying brain processes are manifest in a marked deterioration in memory and cognition. Numerous risk factors such as aging are associated with, and exacerbate, the loss of function in AD brain [3]. Importantly, the multiple processes and risk factors contributing to the slow progression of $\mathrm{AD}$ pathology compromise therapeutic strategies for treatment of the disease.

Transplantation of neural stem cells (NSC) constitutes a putative therapeutic maneuver for cell replacement in brain damage due to their intrinsic properties of self-renewal and capability for differentiation into different cell types including neurons. However, evidence also suggests stem cell therapy may confer neuroprotection by means other than cell replacement including the enhancement of neurotrophic factors [4] or by diminishing levels of putative neurotoxic factors. In the latter case, recent work has indicated efficacy of NPC may involve inhibition of inflammatory factors and responses [5,6]. Overall, beneficial effects of stem cell administration have been reported in a number of animal models including multiple sclerosis [7], Parkinson's disease [8] and stroke [9]. A recent study [10] has provided the first report for use of stem cell therapy in $\mathrm{AD}$ with the finding that transplantation improved cognitive performance in transgenic mice by elevation of brain-derived neurotrophic factor (BDNF).

Since chronic inflammation is a critical facet of AD brain, we reasoned that transplantation of neural progenitors could serve as a feasible strategy to attenuate ongoing inflammatory reactivity and thereby protect neurons. Furthermore, capacity for neural progenitors to engage in chemotactic activity has recently been reported $[11,12]$, a necessary requirement for increased mobility in response to inflammatory factors. We have tested this hypothesis by measuring migration of transplanted neural progenitor cell (NPC) and effects of NPC transplantation on inflammatory responses mediated by microglia and astrocytes, levels of the proinflammatory cytokine, TNF- $\alpha$ and neuronal viability in an animal model of inflamed AD brain. This model uses intrahippocampal injection of amyloidbeta peptide $\left(A \beta_{1-42}\right)$ to induce marked inflammatory reactivity with concomitant neuronal damage in rat brain $[13,14]$.

\section{Methods}

\section{Neurosphere cultures}

Spheres of neural progenitor cells were grown from dissociated telencephalon tissue of $14 \mathrm{~d}$ Sprague-Dawley rat embryos in neurobasal medium (GIBCO) containing B27 (GIBCO) supplement with $20 \mathrm{ng} / \mathrm{ml}$ basic fibroblast growth factor (bFGF) (PeproTech), $10 \mathrm{ng} / \mathrm{ml}$ epidermal growth factor (EGF) (PeproTech) and $10 \mathrm{ng} / \mathrm{ml}$ leukemia inhibitory growth factor (LIF) (Chemicon). The procedure of changing culture medium every 3 days results in the formation of neurospheres [15].

\section{Immunostaining of neurospheres}

Neurospheres were plated on $12 \mathrm{~mm}$ round cover glass (Deckglaser). Spheres were fixed in $4 \%$ paraformaldehyde for $10 \mathrm{~min}$, permeabilized in $0.1 \%$ Triton X-100 (Sigma) in PBS for $5 \mathrm{~min}$, blocked in 5\% normal goat serum (NGS) in phosphate buffered saline (PBS) for 1 hour, and incubated at $4{ }^{\circ} \mathrm{C}$ overnight with the following primary antibodies: antinestin (1:200; Chemicon), anti-vimentin (1:500; Sigma), anti-microtubule associated protein-2 (MAP-2) (1:1000; Chemicon), anti-glial fibrillary acidic protein (GFAP) (1:100; Sigma), and anti-green fluorescent protein (GFP) (1:1000; Invitrogen). The spheres were subsequently incubated with anti-mouse and anti-rabbit secondary antibodies conjugated to Alexa Fluor 488 and 555 (IgG, 1:1000; Molecular probes) for 1 hour at room temperature. The spheres were then incubated in 4',6-diamidino-2-phenylindole dihydrochloride (DAPI) (1:1000; Sigma) for $30 \mathrm{sec}$ and coverslipped in polyvinyl alcohol mounting medium with DABCO-antifade solution (Sigma). Control immunostaining was performed by omission of the primary antibody. Fluorescent images were obtained from a Leica DMIRE2 deconvolution microscope using the software OpenLab 3.7.

\section{Stereotaxic injection of fibrillar $A_{1-42}$}

All experimental procedures were approved by the University of British Columbia Animal Care Ethics Committee, adhering to guidelines of the Canadian Council on Animal Care. Full-length peptide ( $\mathrm{A} \beta_{1-42}$; California Peptide) was prepared as previously described $[16,17]$. The compounds were first dissolved in $35 \%$ acetonitrile (Sigma) and further diluted to $500 \mu \mathrm{M}$ with incremental additions of PBS with vortexing. The peptide solution was subsequently incubated at $37^{\circ} \mathrm{C}$ for $18 \mathrm{hr}$ to promote fibrilization and aggregation and stored at $-20^{\circ} \mathrm{C}$. Intrahippocampal injection of $A \beta_{1-42}$ was performed as previously described $[13,14]$. In brief, male Sprague-Dawley rats (Charles River) weighing 280-300 g were anesthetized (ketamine/xylazine, i.p.) and placed in a stereotaxic apparatus (David Kopf Instruments, Tujunga, CA) and received unilateral injection of $2 \mathrm{nmol} \mathrm{A} \beta_{1-42}$ at the following coordinates: anteriorposterior (AP): $-3.3 \mathrm{~mm}$, mediallateral (ML): $-1.6 \mathrm{~mm}$, (dorsoventral) DV: -3.6 $\mathrm{mm}$, from bregma [18]. Control animals received injection of PBS at these coordinates.

\section{Transplantation of GFP labelled neural progenitor cells}

Dissociated neural progenitor cells in Hank's balanced salt solution were transduced with lentiviral vectors carry- 
ing an enhanced green fluorescent protein (pHR'-CMVGFP). The efficiency of GFP expression levels was quantified in vitro. Approximately $5 \times 10^{5} \mathrm{NPCs}$ were seeded and infected with 3-fold higher titre lentivirus (compared with seeded cell density) in $12 \mathrm{~mm}$ converslips in vitro. Three days after infection, NPCs were fixed with 4\% PFA and placed under a fluorescence microscope for GFP measurement: the results showed approximately $40 \%$ of NPCs expressed GFP expression.

The transduced neural progenitor cells (NPC-GFP; $5 \times$ $\left.10^{4}, 3 \mu \mathrm{l}\right)$ were then stereotactically transplanted $(0.20 \mu \mathrm{l} /$ min) into the hippocampus. Site of transplantation was chosen close to the peptide injection site at the following coordinates from bregma (AP: $-3.3 \mathrm{~mm}, \mathrm{ML}:-1.8 \mathrm{~mm}$, DV: $-3.2 \mathrm{~mm}$ ) as previously described [19]. For control cell graft, dead NPC were prepared by repeated cycles of freezing and thawing and used as control graft [20]. Transplantation was performed three days after PBS and $A \beta_{1}$. ${ }_{42}$ injection. Immunosuppressive agents were not used in the transplantation protocols due to the possibility of anti-inflammatory effects of the agents that could complicate immune-modulatory actions of NPC in vivo.

\section{Immunohistochemical analysis}

Seven days after NPC transplantation, rats were anesthetized and killed by transcardiac perfusion of saline, followed by $4 \%$ paraformaldehyde. Brains were then removed, post-fixed, cryoprotected, and sectioned into 40 $\mu \mathrm{m}$ throughout the hippocampus [14]. Free-floating sections were processed for immunohistochemistry as described previously [14]. Briefly, sections were permeabilized in $0.2 \%$ Triton X-100, blocked with $10 \%$ NGS, and incubated overnight at $4{ }^{\circ} \mathrm{C}$ with the primary antibodies: anti-GFP (1:1000; Invitrogen), anti-ionized calciumbinding adapter molecule 1 (Iba-1, 1:1000; Wako Chemicals), anti-GFAP (1:1000; Sigma), anti- tumor necrosis factor-alpha (TNF- $\alpha, 1: 200$; Cedarlane Laboratories Ltd), and anti-MAP-2 (1:500; Sigma). Sections were incubated with secondary antibodies for 1 hour at room temperature, mounted on Superfrost/Plus microscope slides (Fisher Scientific), and coverslipped. For immunostaining controls, primary antibodies were omitted from the staining procedures. For double immunofluorescence staining, free-floating sections were incubated overnight at $4{ }^{\circ} \mathrm{C}$ with primary antibody to GFP (1:1000; Invitrogen) with nestin (1:500; Chemicon), GFAP (1:1000; Sigma), or MAP-2 (1:500; Sigma) and incubated for $1 \mathrm{hr}$ with a mixture of Alexa Fluor-conjugated 488 anti-rabbit IgG (1:100; Molecular Probes) and Alexa Fluor 594-conjugated antimouse IgG (1:100; Molecular Probes). Immunofluorescence images were examined under a Zeiss Axioplan 2 fluorescent microscope (Zeiss) using a DVC camera (Diagnostic Instruments) with Northern Eclipse software (Empix Imaging) and analyzed for colocalization of staining using National Institutes of Health Image J.

\section{Cell-associated immunostaining}

The extents of microgliosis (Iba-1 marker), astrogliosis (GFAP marker) and TNF- $\alpha$ immunoreactivity (ir) induced by intrahippocampal $A \beta_{1-42}$ or control PBS injections, were evaluated by measuring the marker pixel intensities from five hippocampal sections [14,21]. Immunostaining was done over the specific areas of dentate gyrus, molecular layer (ML) and granule cell layer (GCL). The immunostained section images were digitized and analyzed using the image analysis program NIH version 1.57 (Wayne Rasband, NIH). The overall neuronal viability was assessed by measuring the ir of MAP-2 staining in the ML and GCL of the hippocampus. All quantitative analyses were performed in a blinded manner.

\section{Statistical analysis}

All data are expressed as means \pm SEM. Statistical significance of differences for group comparisons was assessed using analysis of variance followed by Bonferroni's post hoc test or Student's $t$ test. Significance was set at $p<0.05$.

\section{Results \\ Patterns of distribution and differentiation of transplantedNPC, in vivo}

Initial studies demonstrated that cultured NPC expressed characteristic markers for undifferentiated stem cells including nestin and vimentin; NPC also expressed the astrocytic marker, GFAP but not neuronal MAP-2 (data not shown). As shown in Fig. 1A, successful transduction of lentiviral vector-GFP was demonstrated in cultured NPC prior to cell intrahippocampal transplantation. Transplantation of GFP-labeled NPC into the dentate gyrus was carried out 3 days subsequent to intrahippocampal injections of control PBS or $A \beta_{1-42}$ (at $2 \mathrm{nmol}$ ). Immunohistochemical analysis was carried out at $7 \mathrm{~d}$ following NPC transplantation ( $10 \mathrm{~d}$ post-A $\beta_{1-42} / \mathrm{PBS}$ injection). Representative GFP immunostaining, in the molecular and granule cell layers (ML and GCL), indicated increased numbers of NPC in the vicinity of $A \beta_{1-42}$ (right panel, Fig. 1B), compared with PBS (left panel, Fig. 1B), injection site. In order to assess dispersion and net migration of NPC from the site of transplantation, immunoreactivity (ir) of GFP (+)ve cells was measured in regions between the sites of peptide/PBS injection and NPC transplantation. The results (Fig. 1C) demonstrated considerably increased GFP ir in these areas in $A \beta_{1-42^{-}}$ injected, relative to PBS-injected, hippocampus. Overall, area density of GFP ir was increased by $\times 2.8$-fold with peptide, compared with PBS, injection.

Undifferentiated NPC exhibit a number of cell-specific properties and markers such as nestin. We examined for expression of characteristic properties of transplanted cells in vivo in peptide-injected hippocampus. Representative staining patterns of GFP with the different cellular markers (nestin, GFAP and MAP-2) are presented in Fig. 2. 
A in vitro

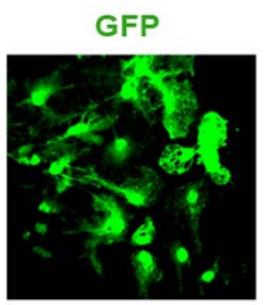

$\mathbf{B}$ in vivo
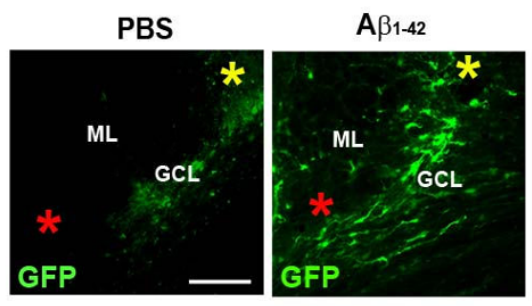

C

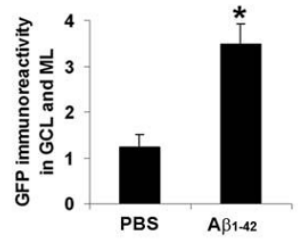

Figure I

GFP-labelled NPC in vitro and diffusion of GFP (+)ve NPC in vivo. (A) GFP staining of cultured NPC. (B) Representative immunostaining for GFP (+)ve NPC in molecular $(M L)$ and granule cell $(G C L)$ layers of dentate gyrus for PBS and $A \beta_{1-42}$-injected rat brain, scale bar is for $100 \mu \mathrm{m}$. The site of PBS or $A \beta_{1-42}$ injection is indicated by a red asterisk; the location of NPC transplantation is indicated by a yellow asterisk. (C) Quantification of GFP ir in region between site of injection (A $\beta_{1-42}$ or PBS) and site of NPC transplantation $(N=4$ animals/group, $*$ denotes $p<0.05)$.

Results from double-immunostaining analysis demonstrated GFP-labeled cells to express nestin and GFAP (Fig. 2, upper and middle panels). Overall, we found in excess of $90 \%$ of NPC showed expression of both nestin and GFAP. However, no evidence for MAP-2 colocalization with GFP was found in $A \beta_{1-42}$-injected hippocampus (Fig. 2 , lower panels). The lack of MAP-2 association with GFP ir suggests that with short term transplantation little or no NPC differentiated into neurons.

\section{Effect of NPC on $A_{1-42}$-induced inflammatory reactivity}

The results shown in Fig 1 indicate NPC migration in response to intrahippocampal $A \beta_{1-42}$-injection. Since microgliosis and astrogliosis are upregulated after peptide injection, gliosis could be modulated in the presence of NPC grafting. To examine this point, the effects of $7 \mathrm{~d}$ NPC transplantation on microglial and astrocyte inflammatory responses and levels of the proinflammatory cytokine, TNF- $\alpha$ were examined in five animal groups; $A \beta_{1-42}$ or PBS injected rat hippocampus, $A \beta_{1-42}$ plus NPC, $\mathrm{A} \beta_{1-42}$ plus dead NPC and NPC alone; PBS served as a control for peptide injection and dead NPC were used as a control for NPC.

Representative immunostaining for microglia (Iba-1 marker), localized to areas between injection $\left(A \beta_{1-42}\right.$ or
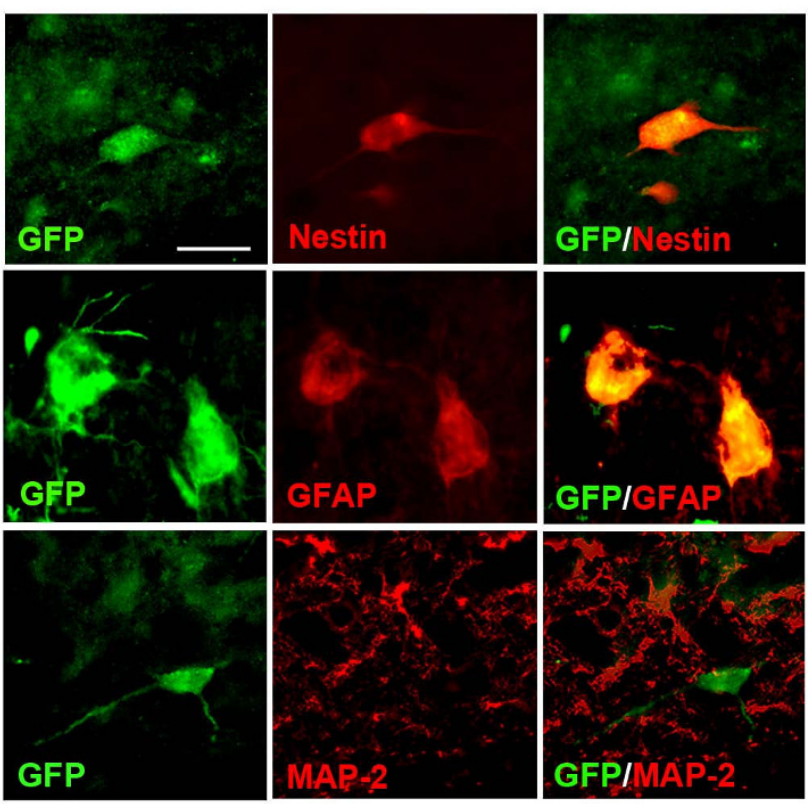

Figure 2

Expression of markers in injected NPC. Representative double staining for GFP association with nestin (upper panel), GFAP (middle panel) and MAP-2 (bottom panel), scale bar = $10 \mu \mathrm{m}$.

PBS) sites and NPC transplantation site, is shown for the different experimental groups ( $10 \mathrm{~d}$ post- $\mathrm{A} \beta_{1-42} / \mathrm{PBS}$ injection) in Fig. 3A (upper panels). Peptide-injected brain demonstrated a considerably elevated Iba- 1 ir compared with PBS-injection. NPC transplantation in $\mathrm{A} \beta_{1-42^{-}}$ injected animals showed efficacy in reducing extents of Iba-1 ir, however, transplantation of dead NPC with peptide was ineffective in reducing microglial proliferative responses. NPC transplantation alone showed a pattern of Iba-1 ir similar to PBS control. Quantification of data is presented in Fig. 3B (left bar graph). Overall, microgliosis (measured as area density of Iba- 1 ir in ML/GCL) was increased $\times 4.3$-fold in $A \beta_{1-42}$, relative to PBS, injected brain. Transplantation of NPC in peptide-injected animals significantly reduced microgliosis (by 38\%) compared with $\mathrm{A} \beta_{1-42}$-injected animals receiving no transplantation. Levels of Iba-1 ir were not significantly altered with application of dead NPC in peptide-injected animals. NPC transplanted animals, in the absence of peptide administration, showed low extents of microgliosis.

Representative immunofluorescent staining for GFAP, in the same regions used for analysis of microgliosis, is shown in Fig. 3A (middle panels) for the different animal groups. Peptide-injected brain exhibited an increased GFAP ir relative to PBS control. Interestingly, levels of 

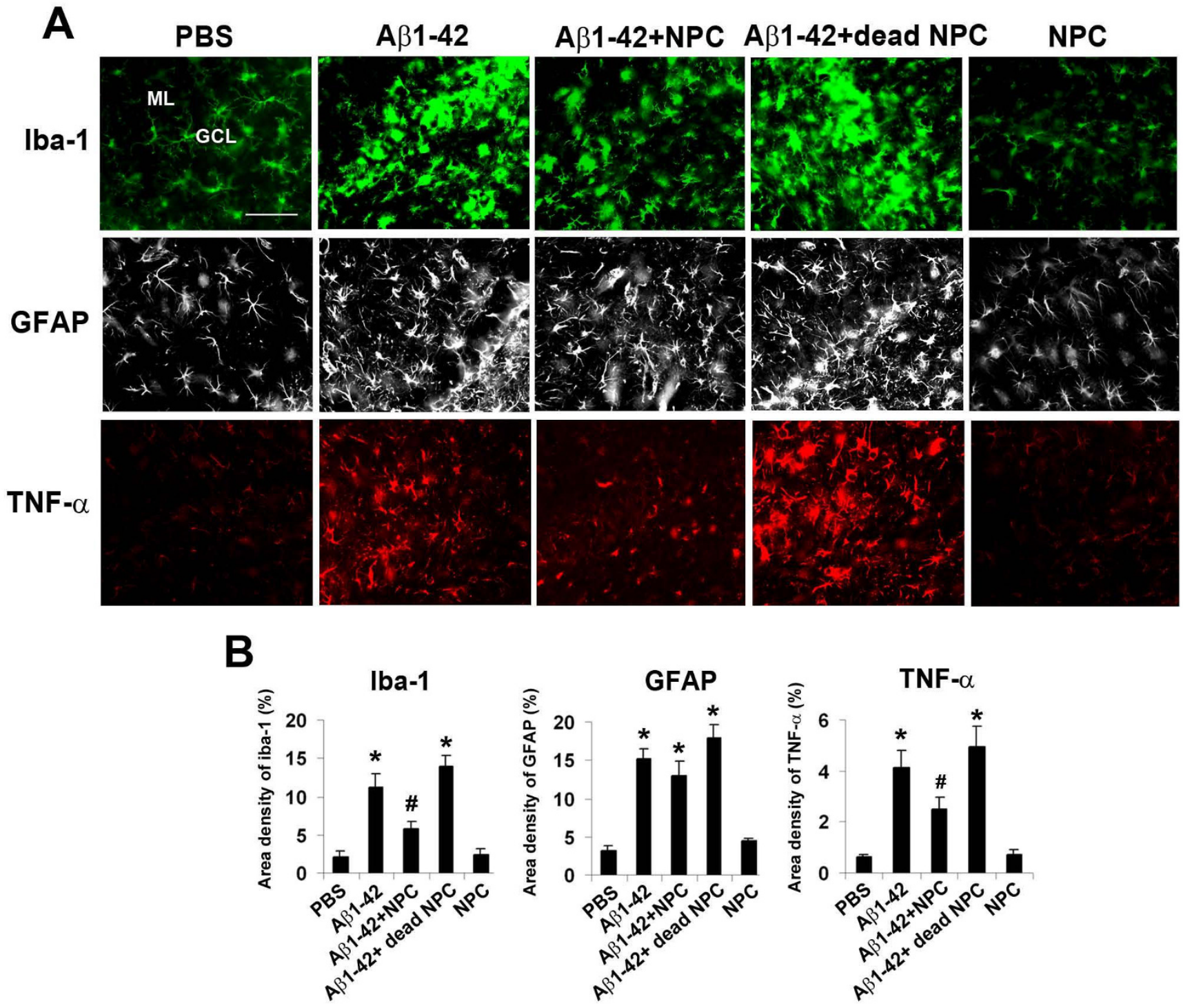

Figure 3

Effects of NPC transplantation on inflammatory reactivity. (A) Representative staining for microglial responses (Iba- I marker, upper panels), astroglial responses (GFAP marker, middle panels) and levels of TNF- $\alpha$ (lower panels) in GCL and ML following $10 \mathrm{~d}$ intrahippocampal injections of PBS/A $\beta_{\mathrm{I}-42}$ and $7 \mathrm{~d}$ transplantation of NPC/dead NPC. The animal groups (panels, left to right) are for PBS, $A \beta_{I-42}, A \beta_{I-42}+$ NPC, $A \beta_{I-42}+$ dead NPC and NPC alone, scale bar represents I00 $\mu$ m. (B) Quantification of data for lba-I (left bar graph), GFAP (middle bar graph) and TNF- $\alpha$ (right bar graph) for the different animal groups $\left(N=5\right.$ animals/group, $*$ denotes $p<0.05$ compared with PBS, \# denotes $p<0.05$ compared with $\left.A \beta_{I-42}\right)$.

astrogliosis appeared relatively unchanged in $A \beta_{1-42^{-}}$ injected rats receiving NPC transplantation. GFAP ir in animals receiving transplantation alone was similar to marker ir with PBS control injection. Quantification of data (Fig. 3B, middle bar graph) showed astrogliosis to be significantly increased $(\times 4.6$-fold $)$ in peptide, relative to PBS, injected rat brain. Although a small decrease in GFAP ir was measured (14\%) with NPC transplantation in peptide-injected brain, this effect was not significant. Extents of GFAP ir were not significantly different between animals receiving $A \beta_{1-42}$ and $A \beta_{1-42}+$ dead NPC or between groups administered PBS injection and ones receiving NPC transplantation alone.

Expression of TNF- $\alpha$ was minimal in PBS-injected hippocampus with high expression of the cytokine evident in peptide-injected brain (Fig. 3A, lower left panels). Transplantation of NPC, but not dead cells, was highly effective 
in attenuating expression of TNF- $\alpha$ in peptide-injected hippocampus. NPC transplantation alone had no effect to alter levels of the cytokine compared to PBS control. Overall, expression of TNF- $\alpha$ in ML/GCL was increased $\times 6.7$ fold in $A \beta_{1-42}$, compared with PBS, injected hippocampus (Fig. 3B, right bar graph). Transplantation of NPC into peptide-injected brain significantly reduced levels of the pro-inflammatory cytokine, by $40 \%$, compared with $\mathrm{A} \beta_{1 \text {. }}$ ${ }_{42}$ injection alone. No significant differences in TNF- $\alpha$ ir were measured between peptide and peptide plus dead NPC animal groups or between PBS injected, and NPC transplanted, brain.

\section{Effect of neural progenitors on $A_{1-42}$-induced neuronal injury}

A critical objective of this work was to determine efficacy of NPC transplantation on neuronal viability. The region of study was the same as for assessment of NPC migration and gliosis, localized to areas between injection and transplantation sites. Representative high magnification patterns of immunostaining for neurons (MAP-2 marker) are presented for PBS and $A \beta_{1-42}$ injected hippocampus (Fig. $4 \mathrm{~A})$. The results indicate a considerable loss of MAP-2 (+)ve neurons with $A \beta_{1-42}$, compared to PBS, injection (Fig. 4A, left panels). NPC transplantation in peptide- injected animals (Fig. 4A, second panel from right) was effective in attenuating the loss of neurons. Dead NPC were ineffective when applied in peptide-injected brain (data not shown). The control NPC graft alone (Fig. 4A, right panel) presented a similar pattern of MAP-2 ir as found with PBS injection. Overall ( $\mathrm{N}=5$ animals/group), MAP-2 ir in ML and GCL was diminished by $45 \%$ in $A \beta_{1 \text {. }}$ 42 , relative to PBS, injected animals (Fig. 4B). Animals receiving NPC transplantation showed a significant $(26 \%)$ increase in numbers of MAP-2 (+)ve neurons compared to peptide-injected animals not receiving NPC treatment. Levels of MAP-2 ir were not significantly different between $A \beta_{1-42}$ alone and $A \beta_{1-42}$ plus dead NPC or between PBS-injected and NPC-transplanted animals.

\section{Discussion}

The primary objective of this study was to provide evidence for the potential clinical utility of NPC transplantation in $\mathrm{AD}$ brain. The major findings from the work are that NPC transplantation significantly inhibits inflammatory reactivity and provides neuroprotection in the $\mathrm{A} \beta_{1-42^{-}}$ injected rat hippocampus. The results constitute the second report of beneficial effects of stem cell treatment in $\mathrm{AD}$; a recent study has demonstrated improvement in cognitive behaviour in transgenic animals with effects attrib-
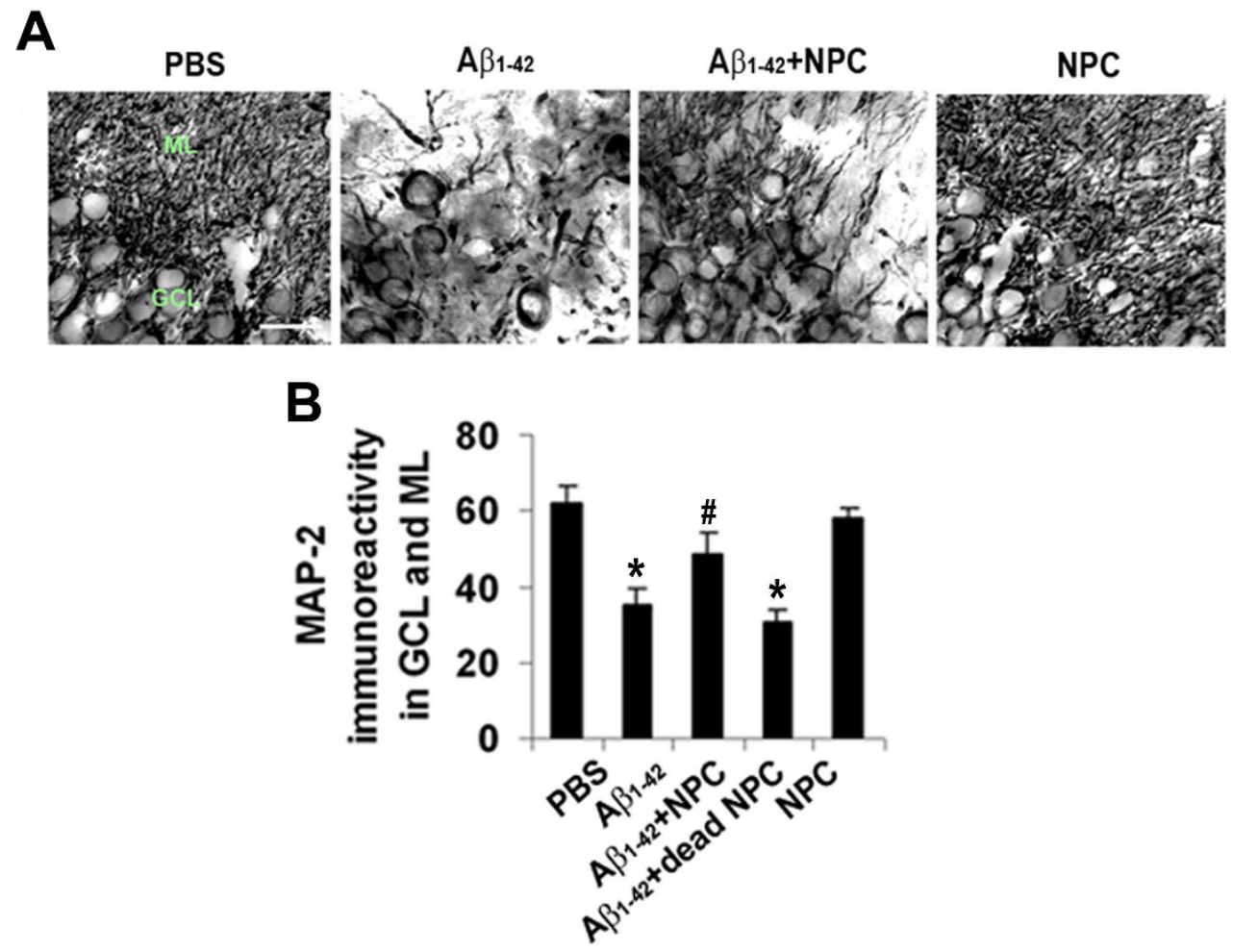

Figure 4

Effects of NPC transplantation on neuronal viability. (A) Representative high magnification of MAP-2 ir in GCL and ML, scale bar is for $20 \mu \mathrm{m}$. Animal groups (panels left to right) are for PBS, $A \beta_{1-42}, A \beta_{1-42}+N P C$ and NPC alone. (B) The bar graph presents quantification of MAP-2 ir in GCL/ML $\left(N=5\right.$ animal groups, $*$ denotes $p<0.05$ vs. PBS, \# $P<0.05$ vs. A $\left.\beta_{\text {I-42 }}\right)$. 
uted to increased levels of hippocampal BDNF [10]. As discussed below, our data showing correlation between inflammatory reactivity and neuronal viability support the possibility that NPC actions to attenuate inflammatory responses may have utility in reducing neuronal damage in inflamed AD brain.

We found that cultured NPC, isolated from rat brain, exhibited a spectrum of characteristic features of undifferentiated stem cells including expressions of nestin, vimentin and GFAP. Efficient transduction of the cells with GFP was demonstrated for the cultured NPC prior to their in vivo transplantation into rat hippocampus at $3 \mathrm{~d}$ following intrahippocampal injections of PBS control or $A \beta_{1-42}$. At $7 \mathrm{~d}$ following NPC transplantation (10 d after $A \beta_{1-42}$ or PBS), immunohistochemical analysis showed higher dispersed GFP ir between sites of injection and transplantation with peptide, relative to PBS, injection. These results are consistent with $A \beta_{1-42}$ injection stimulating a migration of NPC from transplantation to injection site. However, over the whole hippocampus we observed no evident differences between GFP ir with peptide or PBS injection suggesting that NPC survival was not a factor in our experiments. Double staining in vivo showed prominent immunoreactivity of GFP, colocalized with progenitor cell nestin and GFAP, suggesting a NPC phenotype as undifferentiated cells. No evidence for NPC neuronal differentiation was evident (marker MAP-2), a result which could reflect the relatively short duration of NPC grafting employed in this work.

We conclude migration of NPC from sites of transplantation to sites of injection was enhanced in peptide-injected, compared to PBS-injected, hippocampus. These findings would be consistent with the presence of chemotactic stimulatory signals which increase NPC mobility in peptide-injected brain. The initiating stimulus for induction of increased NPC migration could be due to direct deposition of $A \beta_{1-42}$ or indirectly due to signals from microglia (see below) that have been activated by peptide. In the latter case, we have documented that injection of $A \beta_{1-42}$ into dentate gyrus is a potent stimulus for induction of microglial chemotactic responses mediated by a specific receptor for vascular endothelial growth factor (VEGF) [21]. Interestingly, recent work has reported stromal cell derived factor- 1 and its receptor CXCR4 as modulators of progenitor cell migration in the dentate gyrus $[11,12,22]$.

Intrahippocampal injection of $A \beta_{1-42}$ was associated with considerable increases in microgliosis and astrogliosis compared with PBS control. Transplantation of NPC after $\mathrm{A} \beta_{1-42}$ injection significantly inhibited microgliosis, but not astrogliosis, in proximity to peptide injection site. Microgliosis was not altered with dead NPC administered to peptide-injected hippocampus and NPC transplanta- tion alone was associated with similar levels of gliosis as for PBS injection. Cytokine levels are enhanced in AD brain [23] and our results showed elevated TNF- $\alpha$, a proinflammatory cytokine with autocrine function in microglia [24], in $\mathrm{A} \beta_{1-42}$-injected hippocampus. Administration of NPC, but not dead progenitor cells, attenuated levels of TNF- $\alpha$. As discussed below, the effects of NPC grafting to inhibit microgliosis and levels of TNF- $\alpha$ may be correlated.

The injection of $A \beta_{1-42}$ was associated with a loss of neuronal viability, compared with PBS control injection, consistent with previous findings $[14,16,17]$. Importantly, transplantation of NPC, but not dead cells, was effective in diminishing loss of neurons in peptide-injected brain. Although underlying neuroprotective mechanisms are not well understood, this result could be linked with the finding that NPC transplantation was efficacious in attenuating microgliosis with no significant actions to alter astrogliosis. One possibility to account for effects of NPC on microglial responses is that peptide-induced activation of microglia increases their production of chemokines including monocyte chemoattractant protein-1 (MCP-1) [25] and interleukin-8 (IL-8) [26]. In this event preferential migration of NPC to areas exhibiting microglial proliferative responses may follow. Increased migration of stem cells induced by microglia [27], and specifically by the factor MCP-1 [28], have been reported, in vitro. Subsequent NPC release of neurotrophic factors [10] could then inhibit microglial activation by blocking cell-specific inflammatory factors such as major histocompatibility class II [29]. Since A $\beta$-stimulated microglia are potent producers of TNF- $\alpha$ [24], NPC-mediated effects to decrease microglial activation would be consistent with the diminished levels of the pro-inflammatory cytokine as found following NPC grafting. Indeed, our results demonstrated very similar extents of reductions (about $40 \%$ ) in microgliosis and levels of TNF- $\alpha$ with NPC transplantation. Previous studies have suggested that pharmacological maneuvers that inhibit microglial activation can attenuate neuronal damage in animal models of $\mathrm{AD}[13,21]$. Overall, our findings are consistent with an enhanced migration of NPC in response to signals from peptide-activated microglia with NPC releasing factors which in turn act to inhibit microglial inflammatory reactivity. At present, however, the specific NPC-dependent factors coupled to reduction in inflammatory responses and neuroprotection have not been determined.

Our results, together with those reported in [10], provide a proof of principle that stem cell therapy could be efficacious in $\mathrm{AD}$. A number of questions need to be addressed in $\mathrm{AD}$ animal models including the nature of microglial signals which mediate NPC migration and NPC-derived factors which modify microglial activation and inflamma- 
tory responses. The production and release of growth factors other than BDNF [10] by NPC could also contribute to increased neuronal viability and enhanced cognition. Another unresolved question is the possibility that NPC could also directly differentiate into functional neurons in diseased brain suggesting the utility of future work in using longer durations of NPC transplantation in AD animal models.

\section{Conclusions}

It must be noted that any benefits in applying stem cell therapy as a treatment in AD are confounded by a number of complex issues including the involvement of multiple factors in disease pathology and the presumed loss of neuronal and synaptic viability in widespread regions of affected brains. Nevertheless, our data are noteworthy in demonstrating neuroprotective efficacy for NPC in an animal model of $\mathrm{AD}$ which likely emphasizes effects of inflammatory activity [30]. Although effects of NPC transplantation to enhance neuronal viability were modest, it is reasonable to assume that increased levels of neuroprotection could be conferred with different transplantation protocols including use of longer times and higher doses of NPC. Overall, our findings taken in association with recent work in transgenic mice [10], suggest that NPC transplantation represents a novel and plausible approach warranting extensive testing in $\mathrm{AD}$ animal models.

\section{Competing interests}

The authors declare that they have no competing interests.

\section{Authors' contributions}

JKR and TC equally carried out experiments and analysis of data. JGM and JKR conceived and designed experiments. JGM and YTW drafted and finalized the manuscript. All of the authors have read and approved the final manuscript.

\section{Acknowledgements}

This work was supported by a grant (to JGM) from Pacific Alzheimer's Research Foundation

\section{References}

I. Akiyama H, Barger S, Barnum S, Bradt B, Bauer J, Cole GM, Cooper NR, Eikelenboom P, Emmerling M, Fiebich BL, Finch CE, Frautschy S, Griffin WS, Hampel H, Hull M, Landreth G, Lue L, Mrak R, Mackenzie IR, McGeer PL, O'Banion MK, Pachter J, Pasinetti G, Plata-Salaman C, Rogers J, Rydel R, Shen Y, Streit W, Strohmeyer R, Tooyoma I, Van Muiswinkel FL, Veerhuis R, Walker D, Webster S, Wegrzyniak B, Wenk G, Wyss-Coray T: Inflammation and Alzheimer's disease. Neurobiol Aging 2000, 2 I:383-42I.

2. Eikelenboom P, Veerhuis R, Scheper W, Rozemuller AJ, van Gool WA, Hoozemans J]: The significance of neuroinflammation in understanding Alzheimer's disease. I Neural Transm 2006, I I3: | 685-1695.

3. de la Torre JC: Alzheimer's disease: how does it start? J Alzheimers Dis 2002, 4:497-5I2.

4. Ostenfeld T, Tai YT, Martin P, Deglon N, Aebischer P, Svendsen CN: Neurospheres modified to produce glial-cell line-derived neurotrophic factor increase the survival of transplanted dopamine neurons. J Neurosci Res 2002, 69:955-965.

5. Ohtaki H, Ylostalo JH, Foraker JE, Robinson AP, Reger RL, Shioda S, Prockop DJ: Stem/progenitor cells from bone marrow decrease neuronal death in global ischemia by modulation of inflammatory/immune responses. Proc Natl Acad Sci USA 2008, 105:|4638-|4643.

6. Kim YJ, Park HJ, Lee G, Bang OY, Ahn YH, Joe E, Kim HO, Lee PH: Neuroprotective effects of human mesenchymal stem cells on dopaminergic neurons through anti-inflammatory action. Glia 2009, 57:13-23.

7. Pluchino S, Quattrini A, Brambilla E, Gritti A, Salani G, Dina G, Galli R, Del Carro U, Amadio S, Bergami A, Furlan R, Comi G, Vescovi AL, Martino $G$ : Injection of adult neurospheres induces recovery in a chronic model of multiple sclerosis. Nature 2003, 422:688-694.

8. Redmond DE Jr, Bjugstad KB, Teng YD, Ourednik V, Ourednik J, Wakeman DR, Parsons XH, Gonzalez R, Blanchard BC, Kim SU, Gu Z, Lipton SA, Markakis EA, Roth RH, Elsworth JD, Sladek JR Jr, Sidman $\mathrm{RL}$, Snyder EY: Behavioral improvement in a primate Parkinson's model is associated with multiple homeostatic effects of human neural stem cells. Proc Natl Acad Sci USA I007, 104:12175-12180.

9. Lee ST, Chu K, Jung KH, Kim SJ, Kim DH, Kang KM, Hong NH, Kim JH, Ban JJ, Park HK, Kim SU, Park CG, Lee SK, Kim M, Roh JK: Antiinflammatory mechanism of intravascular neural stem cell transplantation in haemorrhagic stroke. Brain 2008, | 3 1:61 6-629.

10. Blurton-Jones M, Kitazawa M, Martinez-Coria H, Castello NA, Muller FJ, Loring JF, Yamasaki TR, Poon WW, Green KN, LaFerla FM: Neural stem cells improve cognition via BDNF in a transgenic model of Alzheimer disease. Proc Natl Acad Sci USA 2009, I 06: I3594-13599.

II. Tran PB, Banisadr G, Ren D, Chenn A, Miller RJ: Chemokine receptor expression by neural progenitor cells in neurogenic regions of mouse brain. J Comp Neurol 2007, 500:1007-1033.

12. Miller RJ, Banisadr G, Bhattacharyya BJ: CXCR4 signaling in the regulation of stem cell migration and development. J Neuroimmunol 2008, 198:3 I-38.

13. Ryu JK, McLarnon JG: Minocycline or iNOS inhibition block 3nitrotyrosine increases and blood-brain barrier leakiness in amyloid beta-peptide-injected rat hippocampus. Exp Neurol 2006, 198:552-557.

14. Ryu JK, McLarnon JG: Thalidomide inhibition of perturbed vasculature and glial-derived tumor necrosis factor-alpha in an animal model of inflamed Alzheimer's disease brain. Neurobiol Dis 2008, 29:254-266.

15. Palmer TD, Takahashi J, Gage FH: The adult rat hippocampus contains primordial neural stem cells. Mol Cell Neurosci 1997, 8:389-404.

16. McLarnon JG, Ryu JK, Walker DG, Choi HB: Upregulated expression of purinergic $\mathbf{P} 2 \times 7$ receptor in Alzheimer disease and amyloid- $\beta$ peptide-treated microglia and in peptide-injected rat hippocampus. J Neuropathol Exp Neural 2006, 65:1090- 097.

17. Franciosi S, Ryu JK, Choi HB, Radov L, Kim SU, McLarnon JG: Broadspectrum effects of 4-aminopyridine to modulate amyloid betal-42-induced cell signaling and functional responses in human microglia. J Neurosci 2006, 26: I I 652-I I 664.

18. Paxinos G, Watson C: The Rat Brain in Stereotaxic Coordinates. Elsevier Academic Press; 2005.

19. Ryu JK, Kim J, Cho SJ, Hatori K, Nagai A, Choi HB, Lee MC, McLarnon JG, Kim SU: Proactive transplantation of human neural stem cells prevents degeneration of striatal neurons in a rat model of Huntington disease. Neurobiol Dis 2004, I 6:68-77.

20. Shihabuddin LS, Hertz JA, Holets VR, Whittemore SR: The adult CNS retains the potential to direct region-specific differentiation of a transplanted neuronal precursor cell line. J Neurosci 1995, I 5:6666-6678.

21. Ryu JK, Cho T, Choi HB, Wang YT, McLarnon JG: Microglial VEGF receptor response is an integral chemotactic component in Alzheimer's disease pathology. J Neurosci 2009, 29:3-I3.

22. Bhattacharyya BJ, Banisadr G, Jung H, Ren D, Cronshaw DG, Zou Y, Miller RJ: The chemokine stromal cell-derived factor-I regulates GABAergic inputs to neural progenitors in the postnatal dentate gyrus. J Neurosci 2008, 28:6720-6730. 
23. Griffin WS, Sheng JG, Royston MC, Gentleman SM, McKenzie JE, Graham DI, Roberts GW, Mrak RE: Glial-neuronal interactions in Alzheimer's disease: the potential role of a 'cytokine cycle' in disease progression. Brain Pathol 1998, 8:65-72.

24. Benveniste EN, Benos DJ: TNF- $\alpha$ and IFN- $\gamma$-mediated signal transduction pathways; effects on glial cell gene expression and function. FASEB J 1995, 9:1577- 1584.

25. Lue LF, Walker DG, Rogers J: Modeling microglial activation in Alzheimer's disease with human post-mortem microglial cultures. Neurobiol Aging 2001, 22:945-956.

26. Franciosi S, Choi HB, Kim SU, McLarnon JG: IL-8 enhancement of amyloid beta (Abetal-42)-induced expression and production of pro-inflammatory cytokines and COX-2 in cultured human microglia. J Neuroimmunol 2005, 159:66-74.

27. Aarum J, Sandberg K, Budd Haeberlein SL, Persson MAA: Migration and differentiation of neural precursor cells can be directed by microglia. Proc Natl Acad Sci USA 2003, 100:15983-15988.

28. Widera D, Holtkamp W, Entschladen F, Niggemann B, Zanker K, Kaltschmidt B, Kaltschmidt C: MCP-I induced migration of adult neural stem cells. Eur J Cell Biol 2004, 83:38I-387.

29. Neumann H, Misgeld T, Matsumaro K, Wekerle H: Neurotrophins inhibit major histocompatibility class II inducibility of microglia: Involvement of the p75 neurotrophin receptor. Proc Natl Acad Sci USA 1998, 95:5779-5784.

30. McLarnon JG, Ryu JK: Relevance of $\mathbf{A} \beta_{\text {I-42 }}$ intrahippocampal injection as an animal model of inflamed Alzheimer's disease brain. Curr Alzheimer Res 2008, 5:475-480.

Publish with Bio Med Central and every scientist can read your work free of charge

"BioMed Central will be the most significant development for disseminating the results of biomedical research in our lifetime. "

Sir Paul Nurse, Cancer Research UK

Your research papers will be:

- available free of charge to the entire biomedical community

- peer reviewed and published immediately upon acceptance

- cited in PubMed and archived on PubMed Central

- yours - you keep the copyright

Submit your manuscript here:

http://www.biomedcentral.com/info/publishing_adv.asp
BioMedcentral 